\title{
ACTUALIDAD Y POSIBILIDADES DEL CONFLICTO DE EDIPO EN EL CONTEXTO DEL DEBATE EN TORNO AL BINARISMO SEXUAL. CONSIDERACIONES TRADUCTIVAS EN TORNO AL GESCHLECHT
}

\author{
Ilka Quindeau \\ International Psychoanalytic University Berlin \\ Berlín, Alemania \\ ilka.quindeau@ipu-berlin.de \\ Niklas Bornhauser \\ Universidad Andrés Bello \\ Santiago, Chile \\ niklas.bornhauser@gmail.com
}

\begin{abstract}
RESUMEN / ABSTRACT
El conflicto de Edipo sigue siendo un pivote del psicoanálisis freudiano. En el acontecer psíquico al que hace alusión se establecen la diferencia, tanto a nivel de género como a nivel de generaciones, así como la ambigüedad, dos aspectos que parecen ser indispensables para la conformación de la estructura psicológica. Sin embargo, en muchos casos, esta triangulación está vinculada a las diferencias de género y a las relaciones sociales y biológicas que no resisten un análisis desde el presente, lo que pareciera implicar un cuestionamiento de su validez y actualidad. Se exploran las posibilidades de un modelo edípico estructural más allá de la heteronormatividad y de las limitaciones derivadas de las condiciones históricas de su formulación y recepción.
\end{abstract}

Palabras ClaVe: género, conflicto de Edipo, bisexualidad, traducción. 


\section{ACTUALITY AND POSSIBILITIES OF THE OEDIPUS COMPLEX IN THE CONTEXT \\ OF THE DEBATE ON SEXUAL BINARISM. \\ TRANSLATION CONSIDERATIONS AROUND GESCHLECHT}

The Oedipus conflict remains a pivot of Freudian psychoanalysis. In the psychic event referred to, the difference is established, both at the level of gender and at the level of generations, as well as ambiguity, two aspects that appear to be indispensable for the conformation of the psychological structure. However, in many cases, this triangulation is linked to gender differences and social and biological relationships that do not resist an analysis of the present, which seems to imply a question of its validity and actuality. The possibilities of a structural oedipal model beyond heteronormativity and the limitations derived from the historical conditions of its formulation and reception are explored.

KEYWORDS: Gender, Oedipus conflict, bisexuality, translation.

Recepción: 29/11/2019

Aprobación: 28/02/2020

\section{NOTA PRELIMINAR}

Este texto nace como el resultado de un trabajo de cooperación, realizado en el marco del proyecto Fondecyt regular $\mathrm{n}^{\circ} 1171146$, que implicó una escritura no solo à deux, sino, adicionalmente, una escritura entre dos lenguas. A lo largo de este proceso, que arrancó el 2016 con una conferencia ante la Asociación de psicoterapeutas analíticos de niños y adolescentes (VAKJP) y su ulterior discusión, esta escritura que se despliega en el entre-dos, más allá de los habituales malentendidos, tuvo que enfrentar un particular desafío, a saber, las palabras que Barbara Cassin distinguió como intraducibles, entre ellas: Geschlecht, Gestalt, eigentlich, unheimlich y otras. Mientras que en algunos casos estas dificultades se sortearon optando por un sinónimo, un neologismo o un inserto en cursivas y entre corchetes de la palabra 'original', el caso de Geschlecht, la palabra central de este texto, amerita algunas consideraciones preliminares.

Según el diccionario de los hermanos Grimm, la palabra Geschlecht es una designación colectiva, que, en tanto formación de un sustantivo abstracto, proviene del verbo gislahti, arraigado en el alto alemán antiguo y que se usaba en el sentido de golpear, brotar, retoñar [schlagen], desarrollarse en un cierto sentido, salir a alguien, tener el modo de alguien. Originalmente, habría sido utilizado para identificar la pertenencia o procedencia de ciertos grupos, acaso en el contexto del ordenamiento por estamentos [Ständeordnung]. Por 
consiguiente, se asociaría, desde sus inicios, con el problema del orden y del estatus o de la condición, la categoría. En el medio alemán alto se registra la expresión gesleht(e), que alude a tribu, ascendencia, familia, especie, género, es decir, una acepción genealógica, en el sentido del genus proveniente del latín. En el medio alemán alto tardío empieza a usarse en el sentido del sexus latín, es decir, sexo. Actualmente, Geschlecht se ocupa tanto para hacer alusión al sexo de los gametos, como para designar el sexo de los órganos sexuales o el sexo (biológico) del ser humano. Adicionalmente, se habla de Geschlecht para dar cuenta del genus gramatical, de la modalidad musical (Dur o Moll, mayor o menor) o, también, para referirse a un campo matemático parcial de la teoría algebraica de los números.

Las traducciones en ambas direcciones han sido variadas: por ejemplo, Le Deuxième Sexe de Simone de Beauvoir, originalmente publicado en 1949, ha sido traducido al alemán como Das andere Geschlecht o, en el caso del castellano, como El segundo sexo; en los años 80, Jacques Derrida escribe tres ensayos titulados Geschlecht, en los que opta deliberadamente por no traducir esta palabra, que rastrea en Fichte, Hölderlin y, sobre todo, Heidegger, y el título se mantiene, con pequeñas modificaciones, en inglés, alemán y castellano; la expresión battle of the sexes, proveniente de la teoría del juego y que es también una película de 2017 dirigida por Valerie Faris y Jonathan Dayton, en alemán se conoce como Kampf der Geschlechter, mientras que ha sido publicada en castellano, como La batalla de los sexos; el libro de Judith Butler, publicado en 1990, que lleva por título Gender Trouble: Feminism and the Subversion of Identity, fue traducido al alemán como Das Unbehagen der Geschlechter, mientras que en castellano circula como El género en disputa: Feminismo y la subversión de la identidad.

En este caso, la polisemia del término, irreducible a un vocablo único, más que un déficit o un problema a ser resuelto de manera tajante, nos parece una virtud que hemos querido conservar, traduciéndolo en todos los casos como 'sexo'. Con esto, adicionalmente, nos sumamos a ciertas posiciones que han cuestionado la diferencia entre género y sexo por considerarla una 'solución' insuficiente o no lo suficientemente radical, que, más que abrir un campo problemático, lo zanja precipitadamente. 


\section{DESAFÍOS SOCIALES CONTEMPORÁNEOS PARA EL PSICOANÁLISIS}

Cuatro años atrás, Conchita Wurst ganó el European Song Contest en Copenhague con la canción "Rise like a Phoenix". Thomas Neuwirth, el cantante y artista austriaco, interpreta a un personaje cuya aparición escénica - una mujer hermosa provista de una barba frondosa y oscura- encarna tanto lo masculino como lo femenino, una amalgama que se expresa también en su nombre artístico: Conchita, originalmente el diminutivo del nombre femenino Concepción, es decir, que en el ámbito de habla hispana remite a la inmaculada o purísima concepción, es, asimismo, el diminutivo de concha, la cobertura rígida y exterior de ciertos animales, específicamente, el exoesqueleto de los moluscos y también el caparazón de las tortugas. En el habla vulgar, ya sea de modo afectivo o despectivo, por concha se hace alusión al órgano sexual femenino, tanto en español como en alemán, donde la expresión Muschi, equivalente a pussy o chatte, también puede ser leída como diminutivo de Muschel. A su vez, Wurst es la palabra alemana para decir salchicha o embutido, término que suele emplearse en ambas lenguas para referirse al pene, al órgano sexual masculino. Es decir, ambas palabras, nombre y apellido, tanto por su forma, sus respectivas asociaciones, sus usos y posibilidades en la lengua, remiten, respectivamente, a lo femenino y a lo masculino. La condensación, aparentemente contradictoria, que da como resultado el nombre completo del o de la artista, desafía las habituales costumbres perceptivas y, en un nivel menos inmediato, crítica el orden sexual dicotómico imperante, un orden que también subyace a los conceptos psicoanalíticos más tradicionales.

En el campo del derecho, la equiparación legal de parejas homosexuales y heterosexuales, tal como se expresa, por ejemplo en la legalización del matrimonio entre personas del mismo sexo [gleichgeschlechtliche Ehe], que en Alemania fue implementada el 17 de octubre 2017 y que implica una serie de derechos y obligaciones asociados -tales como derechos de sucesión, derechos contractuales, contratos de mandato, derechos de adopción, derechos tributarios y, por último, derechos sobre el nombre (con lo que volvemos sobre el punto anterior)- representan un desafío para los quehaceres teóricos y prácticos invocados. Las implicancias del cúmulo de derechos aludidos, lejos de estar resueltas definitivamente, generan una serie de interrogantes que, ante su imposibilidad de ser zanjadas en el campo 'de las ciencias', avalado por su pretendida objetividad y neutralidad valórica, 
tarde o temprano nos confrontan con el sustrato moral, no siempre explicitado, de las respectivas teorías y modelos, que, a su vez, no son independientes de normas sociales y actitudes valóricas. Por razones históricas, en muchas teorías hasta el día de hoy la relación entre hombres y mujeres conforma la norma, mientras que las parejas homosexuales representan un desvío, una anomalía, tal como se expresa, de manera ejemplar, en el vocabulario y en las categorías psiquiátricas, donde se ha hablado, y se sigue hablando, de 'invertidos', 'uranismo' (Karl Heinrich Ulrichs), 'sensación sexual contraria' (Carl Westphal), etc. Más que dar cuenta fría e imparcialmente de una realidad material preexistente, mediante estos conceptos se está generando performativamente una realidad sesgada, tendenciosa e injusta. De este modo, la emergencia de la representación de la homosexualidad aparece inscrita en un campo de relaciones de juicos y valores que la sujetan inevitablemente a la jerarquía entre lo normal y lo patológico, lo anormal (Canguilhem 1966), con las respectivas valoraciones morales asociadas. Así, los conceptos que manejamos hasta la fecha-o que nos manejan-aún aguardan ser revisados en cuanto a su heteronormatividad implícita, operante, debido al perjuicio de semejantes prejuicios (de valor) en el ámbito de las personas y de las teorías que aspiran a convertirse en científicas ${ }^{1}$.

Cabe añadir a las consideraciones anteriores que no es solo la orientación sexual la que es reordenada por las correspondientes reformas legales, sino que estas también afectan a la pertenencia, la afiliación [Zugehörigkeit] a un determinado sexo, que siempre implica cierta servidumbre, cierta sumisión, cierto sometimiento [Hörigkeit]. En el año 2013, en el contexto de la modificación del Personenstandsgesetz alemán, a saber, la ley [Gesetz] que regula, (dis) poniendo [setzen], la posición, el puesto, el estado [Stand] de las personas -en castellano o en francés: el estado civil- se creó una tercera categoría, aparte de 'masculino' y 'femenino'. Más allá de sus incidencias prácticas, lo anterior representó un desafío aún mayor para la respectiva formación de teorías. Dicha modificación en la legislación [Gesetzgebung] imperante ha sido interpretada como respuesta, en el plano legal -es decir, del derecho [Recht] $\mathrm{y}$, con ello, también de la justicia [Gerechtigkeit]- a las dificultades y a los

\footnotetext{
Llama la atención, en este contexto, que la palabra homosexualidad, al igual que el nombre artístico Conchita Wurst, es una formación híbrida, atribuida al escritor Karl Maria Kertbeny, compuesta por dos expresiones provenientes de distintas lenguas: $\dot{o} \mu o ́ \varsigma$, homos, griego para 'igual' y sexus, latín para 'sexo'. Aparentemente, la pregunta por la sexualidad pasa por la consideración de las lenguas.
} 
problemas de personas llamadas 'intersexuales', es decir, con características físicas de género equívocas, que psíquicamente no pueden ser identificadas como masculino o femenino ${ }^{2}$. Un cambio en la legislación vigente como el anterior sin lugar a dudas cuestiona radicalmente las dicotomías fundantes de nuestra visión-de-mundo y sacude la comprensibilidad de suyo con la que habitamos nuestra morada. En efecto, cuestiona un principio central de ordenamiento de nuestra sociedad, pues la llamada identidad sexual, la certeza irrefutable y excluyente de ser hombre o mujer, pertenece a las componentes constituyentes más incuestionables no solo de su identidad individual, sino del orden dominante al interior del que dicha identidad se inscribe -y que avala.

Ahora, ¿qué significan estos movimientos en el campo de la lengua y de la ley para la discusión conceptual, en general, y la formación de teorías psicoanalíticas, en particular? Ya en 1933, Sigmund Freud, en su conferencia sobre la feminidad ${ }^{3}$, hace alusión a la naturalidad con la que incorporamos y perpetuamos ciertos preceptos binarios de nuestro sentir, pensar y hacer: "Masculino y femenino es la primera diferencia que ustedes hacen cuando se encuentran con otro ser humano, y están habituados a establecerla con resuelta

2 En este caso, el neologismo se mantiene en una misma lengua, el latín: inter, entre y sexus, sexo. La expresión, propuesta en 1915 por el genetista Richard Goldschmidt, responde a la imposibilidad de dar cuenta de aquellos casos que se encuentran entre los fenotipos masculino y femenino ideales. El uso del término, que aún ha de diferenciarse de los términos vecindados transexualidad, transgender, (pseudo)hermafrodismo y otros, ha sido criticado como patologizante y discriminatorio y da cuenta de las dificultades del pensamiento-lengua de ir más allá de sus propias restricciones históricas sin traicionar los impulsos revolucionarios. Véase: Richter-Appelt, H. y Schweizer, K. (2010). Intersexualität oder Störung der Geschlechtsentwicklung: Zur Behandlung von Personen mit nichteindeutigem körperlichen Geschlecht. Der Psychotherapeut 55(1), 36-42; Schweizer, K. y Richter-Appelt, H. (Hrsg.). (2012). Intersexualität kontrovers. Grundlagen, Erfahrungen, Positionen. Gießen: Psychosozial.

Es notable la incomodidad de Freud al momento de hablar de este tema, tal como se manifiesta en las siguinetes frase iniciales: "Todo el tiempo en que me preparaba para hablarles luché con una dificultad interior. No me siento seguro de mi buen derecho, por así decir. Es verdad que el psicoanálisis ha cambiado y se ha enriquecido en los últimos quince años de trabajo, pero por eso mismo una introducción al psicoanálisis podría quedar intacta y sin complementos. De continuo me acude la idea de que estas conferencias carecen de justificación. A los analistas les digo demasiado poco, y nada, pero nada, nuevo; en cambio, a ustedes les digo demasiado, y cosas tales para cuya comprensión no están preparados, y no son adecuadas para ustedes" (104). Esta conferencia está precedida, aunque no inmediatamente, por la conferencia titulada 'Sobre la descomposición de la personalidad psíquica' (ya se volverá sobre esto). 
certidumbre [unbedenklicher Sicherheit]" (120/105). En estricto rigor, Freud habla no solo de 'certidumbre', como traduce Etcheverry, sino, primero, de 'seguridad' y, en segundo lugar, de una seguridad sin reparos, sin objeciones, que prescinde del pensar [Denken]. Es decir, la seguridad con la que se habita el mundo guarda relación con la renuncia a pensar, al menos radicalmente, ciertas determinaciones condicionantes que recaen en uno, por estableciendo, por ejemplo, lo que puede ser (ya sea fáctica o especulativamente) y lo que no. Sin embargo, esta engañosa seguridad inmediatamente es develada como una ficción, ya que se encuentran partes del género masculino también en el cuerpo de la mujer, y viceversa: "como si el individuo no fuera varón o mujer, sino ambas cosas en cada caso, sólo que más lo uno que lo otro" (120/106). Como es consabido, en este lugar Freud retoma ciertas ideas ya expuestas en sus Tres ensayos sobre teoría sexual (1905), relacionadas con el concepto de bisexualidad.

Pero el elaborado concepto freudiano de una bisexualidad constituyente, ajeno a todo reduccionismo o monismo sexuales, ha sido mantenido a raya de parte del mainstream de la formación psicoanalítica de teorías, y menos al sentido común ilustrado de la llamada comunidad científica, principalmente debido a que ambas parten, y necesitan partir, de la certeza prerreflexiva de la existencia cierta de una identidad inequívoca de sexo - a pesar de que 'identidad' no es un concepto que se encuentre en Freud, y aún menos asociado a la idea de sexualidad. Ciertos desarrollos de Jean Laplanche (2011) interrogan precisamente esta supuesta claridad, despojada de cualquier ambigüedad, que se expresa, por ejemplo, en la manera en que parten casi todos los casos clínicos. La inaugural constatación-descriptiva, fenomenológica, basada en la 'evidencia, despojada de cualquier conflicto- del sexo, que se expresa en fórmulas como "Consulta un hombre de 30 años..." o "Una mujer de 25 años se queja de...", no hace sino abrir un espacio discursivo que no solamente suscribe esta diferencia, sino que la propaga y avala activamente. Prácticas discursivas como estas, que desmienten cualquier ambigüedad, inseguridad $\mathrm{y}$ faltas de univocidad respecto de la identidad sexual, reafirman el hecho de que para los lactantes el mundo está dividido binariamente en celeste y rosado. Incluso antes de su nacimiento físico, su llegada al mundo, los infans son referidos de una manera específica, que se corresponde de manera normalizada con su respectivo sexo, y no de otra. Estos modos de emplazar, referirse a y relacionarse con ellos tienen como fundamento la convicción, sino la fe, de que el mundo está dividido, de manera excluyente y sin residuos, en niños y niñas. Es a este mundo, estructurado por la bisexualidad, respectivamente, por 
la fe ciega y apodíctica en la pertinencia e irrefutabilidad de dicha división, que los infans son arrojados.

\section{EL COMPLEJO DE EDIPO COMO PUNTO NODAL PARA LA FORMACIÓN DE SEXUALIDAD Y SEXO}

En el campo del psicoanálisis, los conceptos de identidad sexual -que, como ya hicimos notar, no tiene asidero alguno en la obra de Freud, ni de Lacan, para nombrar solamente a algunos de sus máximos exponentes- $\mathrm{y}$ de orientación sexual, otra importación (o impostación) discursiva, están relacionados, incluso amalgamados, entre sí a través del complejo de Edipo. La infinita multiplicidad polimorfa, que excede las tradicionales distinciones de sexo, la vasta abundancia rizomática de diferentes modalidades de experimentar o causar placer (o displacer), el sinnúmero de modos de satisfacer, aunque siempre incompletamente, la pulsión, se topa con dos principios fundamentales, que se oponen a esta proliferación infinita de formas: el complejo de Edipo y la primacía genital. En el trazo que deja el complejo de Edipo, se establece la diferencia generacional y la diferencia sexual que implica la pertenencia indudable y demostrada a uno de ambos sexos, mientras que los componentes heterosexuales, es decir, pertenecientes al otro sexo y que pudieran entablar relaciones conflictivas o contradictorias con las anteriores, son reprimidas tornándolas inconscientes. Es decir, el complejo de Edipo es el soporte de la inscripción de ciertos principios sociales de ordenamiento, en este caso, la dicotomía de los sexos, en la estructuración psíquica, volviendo al respectivo sujeto en soporte [Träger] del orden establecido entre las fuerzas sociales.

La pregunta que quisiéramos desarrollar en este contexto es la siguiente: considerando, por un lado, los antecedentes sociales y culturales expuestos con anterioridad y, por el otro, la necesaria revisión crítica de sí que hace parte de las prácticas fundacionales del mismo psicoanálisis (Bornhauser 2009), ¿cuál es, en el presente, la validez y vigencia de dicho conflicto? Con respecto a esto, en primer lugar, quisiéramos reconstruir, aunque esquemáticamente, la relevancia y función del conflicto de Edipo en y para Freud, para luego, en un segundo momento, ponerlo en relación con la llamada situación general de seducción. No está de más señalar que la referencia a Freud no responde a afán autoritario alguno, acaso a la voluntad (de poder) de emplazar la palabra del padre y amo del psicoanálisis al modo de un argumentum ad verecundiam, sino al deseo de volver a leer a Freud, de revisitar sus textos, con tal de interrogarlo 
desde coordenadas contemporáneas, poniendo a prueba su capacidad para pensar críticamente el presente. En lo que sigue, apuntaremos a mostrar que la heteronormatividad en ocasiones asociada al Edipo perfectamente puede ser evitada, al menos en su mayor medida, rehaciendo sus relaciones con las fuerzas del ordenamiento opresor y propondremos comprender a dicho conflicto como punto nodal de la apropiación psíquica de diferencia y ambigüedad, un aspecto clave para la localización emancipatoria de sí en una red social de relaciones de reciprocidad.

\section{EL COMPLEJO DE EDIPO EN EL PSICOANÁLISIS FREUDIANO}

El punto culmine y, al mismo tiempo, el cierre de la fase fálica en la organización genital infantil, es conformado por el complejo de Edipo. Juega un rol fundamental en la estructuración -y desestructuración, véanse las observaciones freudianas sobre la descomposición, el desmantelamiento, el desarme o la desarticulación [Zerlegung] de la psique (Freud 1933)- de la personalidad en general y de la sexualidad humana en particular. A pesar de su relevancia central, Freud, salvo, quizá en el texto titulado El sepultamiento [Untergang] del complejo de Edipo (1924) -en el cual justamente habla de su hundimiento, su sepultura- no desarrolló sistemáticamente este concepto y menos en un texto exclusivamente dedicado a este problema, de manera que su delimitación y diferenciación es una tarea pendiente que necesariamente ha de pasar por una (re)lectura de sus escritos.

En su célebre texto Tres ensayos sobre teoría sexual de 1920, Freud, en una nota al pie [sic] agregada en 1920, formuló la relevancia del complejo de Edipo:

Se ha dicho con acierto que el complejo de Edipo es el complejo nuclear de las neurosis, la pieza esencial del contenido de estas. En él culmina la sexualidad infantil, que, por sus consecuencias, influye decisivamente sobre la sexualidad del adulto. A todo ser humano que nace se le plantea la tarea de dominar el complejo de Edipo; el que no puede resolverla, cae en la neurosis. El progreso del trabajo psicoanalítico ha destacado con trazos cada vez más nítidos esta importancia del complejo de Edipo; su reconocimiento ha pasado a ser el shibbólet que separa a los partidarios del análisis de sus oponentes (Freud 1905, 127, Fn 2/206 np 28). 
Sin embargo, ni en este lugar ni en ningún otro aclara en qué consiste exactamente la relevancia y significación del complejo de Edipo. Resulta más llamativo aún, entonces, que lo convierta nada menos que en shibboleth del discurso psicoanalítico ${ }^{4}$. En el pequeño escrito La organización genital infantil, Freud, como es habitual en él, admite que si bien en un principio había partido -erróneamente- por asumir "una fundamental diversidad [Verschiedenheit] entre la vida sexual de los niños y la de los adultos" (1923b, 293/145), ahora, debido a la evidencia clínica y ciertas exigencias que se desprenden de la teoría, puede reconocer "la notable aproximación del desenlace de la sexualidad infantil (cerca de! quinto año de vida) a su conformación final en el adulto" (1923b, 293/145). Sigmund Freud, en este lugar, cita un inserto que él mismo hizo, en 1915, en los Tres ensayos. Tal como venimos exponiendo, en aquel entonces, aún había partido de la presuposición que, junto a la ya aludida elección de objeto, el aspecto central de la sexualidad en el adulto consiste en la subordinación de las pulsiones parciales a la primacía de lo genital y que es precisamente este aspecto el que falta en la sexualidad infantil. Esta concepción fue rectificada en 1923, cuando enfatizó la presencia y el protagonismo de "el interés por los genitales y el quehacer genital" (1923b, 294/146) ya durante la infancia. A diferencia de la organización genital del adulto, sin embargo, "para ambos sexos, sólo desempeña un papel un genital, el masculino. Por tanto, no hay un primado genital, sino un primado del falo" (1923b, 294/146).

Mientras que el interés de los niños por sus genitales es un hecho indiscutible, la convicción que solo el genital masculino, y no así el femenino, ha de ser relevante, no puede sino producir estupefacción. Y es que el propio Freud en la oración inmediatamente posterior concede que solo está en condiciones de poder describir estas relaciones [diese Verhältnisse] para el varón, debido a que le falta -y le seguirá faltando- el insight en los respectivos procesos en el caso de la niña. Es justamente aquí donde tempranamente, es decir, ya en el debate psicoanalítico contemporáneo a Sigmund Freud, se formularon las primeras y justificadas críticas, como, por ejemplo, la objeción tan vehemente como convincente de Karen Horney (1923) mediante su célebre ensayo sobre la génesis del complejo de castración femenino. Rescatamos, en este lugar,

Sobre el concepto de shibboleth y su relación con la escritura, en clara demarcación de las reflexioens derridianas sobre este concepto, véase Geisenhanslüke, Achim. Das Schibboleth der Psychoanalyse. Freuds Passagen der Schrift. Bielefeld: transcript, 2008. 
que Sigmund Freud había partido de una analogía estructural -y no "de contenido"- del conflicto de Edipo para ambos sexos y que fue recién como resultado de la controversia intrapsicoanalítica que se abandonó la aproximación estructural, reemplazándola por la puesta del foco de atención en las diferencias específicas de cada sexo en particular. Desde una perspectiva actual se puede decir que la crítica feminista, por muy justificada y comprensible que esta haya sido, a mediano plazo condujo hacia un callejón sin salida: al introducir un "complejo de Edipo femenino" autónomo, independiente, que estaba nítidamente delimitado de su equivalente "masculino", inevitablemente se terminó por apoyar la dominación efectual de la codificación binaria del sexo $\mathrm{y}$, con esto, en definitiva, a la heteronormatividad imperante. La consideración del conflicto de Edipo en el contexto contemporáneo solo es viable bajo la forma de un modelo estructural general que deje espacio para la expresión y formación de la pluralidad sexual. La diferenciación 'de contenido', que va de la mano con distintos modelos para describir adecuadamente los cursos evolutivos en varones y niñas, tanto en lo que respecta la orientación heterosexual como homosexual, ya no resulta sostenible. Más bien, se trata, entonces, de describir el modelo de un conflicto de Edipo que valga por igual para varones y niñas, y que esté abierto para las variaciones de sexo y las distintas formas del deseo.

Con tal de encaminar tal conceptualización quisiéramos volver a las reflexiones freudianas. En su ensayo El yo y el ello (1923a), Freud distinguió una forma que llama "positiva" de una forma "negativa" del complejo de Edipo, que -independientemente de la bisexualidad constituyente del niño-juntos integran el complejo de Edipo "completo". La forma positiva se apuntala en el mito edípico y, por consiguiente, describe el amor hacia la parte paterna del otro sexo, que cursa simultáneamente con rivalidad y deseos de muerte hacia aquella parte de la pareja que es del mismo sexo. A su vez, en la forma negativa, el amor le corresponde a la parte de la pareja que es del mismo sexo que el infans, mientras que la rivalidad se dirige al otro sexo: "Es decir que el varoncito no posee sólo una actitud ambivalente hacia el padre, y una elección tierna de objeto en favor de la madre, sino que se comporta también, simultáneamente, como una niña: muestra la actitud femenina tierna hacia el padre, y la correspondiente actitud celosa y hostil hacia la madre" (261/35). La simultaneidad de una elección de objeto homosexual y otra heterosexual, el amor tanto hacia el padre como hacia la madre, en el curso del complejo de Edipo es posibilitada por la bisexualidad constitutiva del ser humano, una expresión que se refiere no solo a la elección de objeto, sino también al sexo. 
Más allá de las controversias y discrepancias en cuanto a su interpretación, actualmente hay un consenso que la concepción freudiana de una "bisexualidad constitutiva" representa una piedra miliar, un hito en la historia de la teoría psicoanalítica, tal como el propio Freud sostiene, nuevamente, en una nota al pie: "Esta observación muestra que en el caso de los seres humanos no hallamos una virilidad o una feminidad puras en sentido psicológico ni en sentido biológico. Más bien, todo individuo exhibe una mezcla [Vermengung] de su carácter sexual biológico con rasgos biológicos del otro sexo" (119120 Fn 1/200, np 19). A nuestro juicio, es de una importancia primordial que Freud arraigue la disposición bisexual inmediatamente en lo corporal, sin mediación alguna. De esta bisexualidad biológica hay que distinguir y separar la bisexualidad psíquica, situada en el plano representacional, y que resulta de la presencia de rasgos masculinos y femeninos adquiridos mediante procesos de identificación con la madre y el padre. A su vez, la naturaleza bisexual también se refleja en el deseo de un objeto sexual que englobe la unificación de ambos caracteres de sexo, el deseo de un hombre y, a su vez, de una mujer (44).

De estas cuatro mociones, es decir, la acuñación, en cada caso, masculina y femenina del llamado conflicto de Edipo positivo y negativo, durante la disolución [Auflösung] del complejo emergen, en paralelo, dos identificaciones: una paterna y una materna. En el caso del varón, la identificación con el padre se aferra, reteniéndolo, al objeto materno del complejo positivo y simultáneamente reemplaza al objeto paterno del complejo negativo; la identificación con la madre transcurre de manera análoga. Este mecanismo del reemplazo [Ersetzung] de una relación objetal por otra, que adquiere más relevancia que cualquier posición [Setzung] originaria, fundante, y que cursa con la introyección del objeto anterior, se encuentra por primera vez en el estudio freudiano sobre Leonardo, en el que describe una evolución homosexual: en esta, el varón, dicho sucintamente, con tal de no traicionarla, reemplaza su amor hacia la madre identificándose con ella (Freud 1910). Ahora, el patrón del reemplazo de una relación de objeto mediante identificación vale para ambas orientaciones sexuales, tanto para las heterosexuales como para las homosexuales. Dicho patrón se distingue únicamente en si es elegida la pareja paterna del mismo sexo o del sexo contrario ${ }^{5}$.

En El yo y el ello (1923a) Freud esboza finalmente la génesis del super-yo a partir de estas identificaciones que ocupan el lugar de las investiduras edípicas de objeto. 
Para Freud, el desenlace de la situación edípica, que puede desembocar en identificaciones paternas o maternas, en ambos sexos depende de la fuerza relativa de las dos disposiciones de sexo, que de acuerdo a la lógica freudiana estarían biológicamente dispuestas; encuentran su expresión en la acuñación, cuya intensidad puede variar, de ambas identificaciones:

\begin{abstract}
Así, como resultado más universal de la fase sexual gobernada por el complejo de Edipo, se puede suponer una sedimentación en el yo, que consiste en el establecimiento de estas dos identificaciones, unificadas de alguna manera entre sí. Esta alteración del yo recibe su posición especial: se enfrenta al otro contenido del yo como ideal del yo o superyó" (Freud, 1923a, 262/35-36).
\end{abstract}

En este lugar, quisiéramos señalar que el concepto de sexo que puede ser leído en Freud, lejos de ser un término restrictivo y coercitivo, mantiene la polisemia inherente al vocablo, invitando a generar distintas interpretaciones potencialmente conducentes a otros campos. Nuestra hipótesis es que es justamente su potencial especulativo, del que se desprende la amenaza de corroer los modos establecidos de pensar, entre ellos su capacidad de disolver la dicotomía entre masculinidad y feminidad, el principal responsable de su 'olvido'. El concepto de la bisexualidad constitutiva, en lugar de reafirmar el esquema binario comentado, arraiga a nivel del cuerpo a componentes de sexo de carácter masculino y femenino, dispuestos en distintas composiciones [Zusammensetzungen]. A esto se agrega la bisexualidad psíquica, que está integrada, de acuerdo a los mecanismos anteriormente aludidos, por identificaciones con ambas partes paternas ${ }^{6}$.

El doble sentido del conflicto de Edipo, que transcurre en una variante homoerótica y otra heteroerótica, va de la mano con la simultaneidad de sentimientos contradictorios, a saber, amor y odio, respectivamente, rivalidad hacia una de las partes paternas. Es decir, en lugar de imponer una matriz reproductiva única, que condena al sujeto a padecer 'lo que ya fue escrito', se abren distintas vías de elaboración de este conflicto, que apuntan a fomentar la tolerancia a la ambigüedad, soportar las contradicciones a nivel afectivo

\footnotetext{
Aparte de lo aquí desarrollado, es importante retener que el superyó ocupa el lugar de la relación de amor abandonada; a través de esto, esta es conservada en tanto introyecto en la estructura psíquica (acerca del modo melancólico del desarrollo del género véase Quindeau 2008 y Butler 1997).
} 
y lógico, habilitando al sujeto en ciernes a tomar distancia, por la vía del ejercicio de la crítica, de cualquier funcionamiento autoritario. Lo mismo vale para la determinación definitiva del objeto de amor, que se establece en dos tiempos, en dos brotes o empellones: concretamente, en la fase edípica y en la pubertad, donde la primera ya predibuja el camino de la segunda. Freud considera que uno de los "logros psíquicos más importantes, pero también más dolorosos, del período de la pubertad" $(1905,128 / 207)$ es el desprendimiento de los padres y el levantamiento de la barrera del incesto, que representa una "exigencia cultural para la sociedad" $(1905,128 / 207)$, mediante la superación y desestimación de fantasías incestuosas. A través de lo anterior, "crea la oposición, tan importante para el progreso de la cultura, entre la nueva generación y la antigua" (1905, 128/207).

Como es consabido, para Freud, el complejo de Edipo en niñas y varones termina de manera desigual. Mientras que en el varón "se estrella [zerschellt] contra la amenaza de castración", es decir, se despedaza estrepitosamente, hundiéndose acompañado de un réquiem entonado por timbres y cascabeles [Schellen], en la niña es "lentamente abandonado", porque no se cumple su deseo de obtener un hijo como regalo del padre (Freud 1924). Esta conceptualización habitualmente ha sido leída como una nueva e injustificada introducción del binarismo, lo que de manea comprensible ha provocado múltiples críticas (de manera más explícita, en Quindeau 2008) y evidenció la necesidad de generar un modelo estructural de carácter general que sea válido para ambos sexos. Los pasos siguientes conforman un intento de avanzar en esta dirección.

Si se examina el curso histórico de la génesis del complejo de Edipo, no puede pasar inadvertido que Sigmund Freud formula su primera concepción de éste al mismo tiempo que abandona la teoría de la seducción ( $c f r$. Cartas a Wilhelm Fließ n ${ }^{\circ} 139,141,142$ de septiembre y octubre 1897, Freud 1986):

Un solo pensamiento de validez universal me ha sido dado. También en mí he hallado el enamoramiento de la madre y los celos hacia el padre, y ahora lo considero un suceso universal de la niñez temprana [...]. Si esto es así, uno comprende el cautivador poder de Edipo rey, que desafía todas las objeciones que el intelecto eleva contra la premisa del oráculo, y comprende por qué el posterior drama de destino debía fracasar miserablemente. [...] Cada uno de los oyentes fue una vez en germen y en la fantasía un Edipo así, y ante el cumplimiento de sueño traído aquí a la realidad objetiva retrocede espantado, con 
todo el monto de represión (esfuerzo de desalojo y suplantación) que divorcia a su estado infantil de su estado actual (Freud, 293/307).

Jean Laplanche (1988, $207 \mathrm{ff}$.) es uno de los autores que ha elaborado críticamente este contexto relacional teórico-histórico entre abandono de la teoría de la seducción y formulación del complejo de Edipo. Con el abandono de la teoría de la seducción, la traumatización que le fue causada al sujeto desde afuera pasa a un segundo plano y en su lugar aparece la relevancia de la realidad psíquica y de la fantasía inconsciente (Parin y Parin-Matthey 1986; Rohde-Dachser 1989; Vogt 1986). Este paso, que hace parte de la historiografía oficial del psicoanálisis, ha sido descrito, por un lado, como deshistorización y, por el otro, como mitologización de la teoría psicoanalítica: esto debido a que Freud, de ahora en adelante, comprende la universalidad de las fantasías edípicas de ahora como herencia filogenética; en otras palabras: el lugar de la historia de vida y de su respectiva perlaboración es ocupado ahora por la filogénesis.

\section{EL COMPLEJO DE EDIPO COMO RESPUESTA A LA SEDUCCIÓN}

En una analogía explícita con la revolución copernicana, cuya relevancia era bien conocida por Freud como testimonian sus consideraciones epistemológicas, Jean Laplanche, a propósito de la misma teoría freudiana, establece la existencia simultánea de una línea copernicana, compuesta por un haz de fuerzas que causan el descentramiento del psiquismo, y de una línea ptolemaica, opuesta a la anterior y que se alternaría con ésta permanentemente, que efectuaría un persistente recentramiento. El mentado giro copernicano sugiere que "el ser humano mismo, en tanto sujeto cognoscente, no es el sistema referencial central de lo que conoce. Así como las estrellas no giran alrededor de él, así tampoco reconocen la primacía de nuestro conocimiento" (Laplanche 1996, p. 11, traducción propia). Este insight respecto del primordial e irreversible descentramiento del sujeto encuentra un precipitado en la concepción de lo inconsciente que Freud en las Conferencias de introducción al psicoanálisis (1916-1917) irónicamente llama la tercera ofensa [Kränkung] narcisista del ser humano, después de las de Copérnico y Darwin. La teoría laplanchiana de la seducción apunta exactamente en esa misma dirección, ya que, a diferencia de la tradición cartesiana, radica los fundamentos-inciertos, volubles, establecidos siempre a posteriori- para el desarrollo de la estructura psíquica no en el 
mismo sujeto, sino en la relación para con otro. Frente a esto, de acuerdo a las categorías introducidas por Laplanche, el complejo de Edipo representa un movimiento recéntrico en la medida en que emplaza al niño, aunque sea en un segundo momento, habilitándolo para erigirse en sujeto de $s u$ deseo.

Laplanche busca mantener el primado del otro, asociado al descentramiento del sujeto, tal como aparece, aunque con matices importantes, en Arnold Gehlen, Jacques Lacan y Niklas Luhmann, en su teoría general de la seducción. Su idea fundamental, dicho abreviadamente, es la siguiente: ante el fondo de la situación antropológica fundamental -que consiste en la condición de ser-arrrojado [Geworfenheit] al mundo, su exposición a un mundo sociosimbólico que lo precede y excede, interpelándolo con significantes que le son ajenos e inteligibles, constituyéndolo como un ser en falta o Mängelwesen-, el encuentro con el otro es concebido como una (des)relación fundamentalmente asimétrica, establecida entre el adulto con un inconsciente ya desarrollado y el infans con una estructura psíquica en vías de constitución. El lactante es confrontado con la demanda [Anspruch] del adulto (en el sentido doble -por un lado, como interpelación, hablarle a alguien, dirigirle la palabra, así como, por el otro, como pretensión, exigencia o demanda), con el mensaje enigmático, inconsciente, atravesado por el deseo sexual, del adulto, que no le es accesible a ninguno de ellos. Con tal de evitar posibles malentendidos: se trata del deseo inconsciente del adulto, tal como inevitablemente es gatillado en toda interacción de los padres con el lactante, es decir, en todos los cuidados [Sorge] que estos le proporcionan a diario. Es decir, en ningún caso -al menos cuando nos movemos en el campo neurótico correspondiente a la ausencia de perversiones y psicopat(olog)ías- se trata de acciones sexuales en el sentido concreto, que respondan a una voluntad consciente, sino del deseo inconsciente que está presente en todos nosotros. Dicho deseo, radicado en el adulto, se dirige hacia el lactante en tanto demanda en el sentido anteriormente comentado. Y, dicho abreviadamente, es a esta demanda que el niño responde con el desarrollo de su propio deseo infantil, sexual. Por lo tanto, el proceso de constitución de la sexualidad y, más allá de esto, de toda estructura psíquica, parafraseando el célebre giro cartesiano cogito ergo sum podría ser formulado de la siguiente manera: desideratus ergo sum. Esta formulación, en la medida en que la forma verbal pasiva alude a las relaciones de sujeción y sometimiento propias de la escena constitutiva de subjetividad -pero, al mismo tiempo, plantea la posibilidad del surgimiento de fuerzas contrarias, opuestas-, posee la virtud de considerar no solo el protagonismo del deseo, por sobre el tradicional predominio atribuido a la 
razón, sino también hace presentes la heteronomía y extimidad fundamentales de la existencia humana.

En la situación universal de seducción, de acuerdo con Laplanche, el deseo del adulto es inscrito [eingeschrieben] en el cuerpo del niño como núcleo de lo inconsciente. Esta inscripción no es que tenga que ser comprendida únicamente en un sentido metafórico, ya que con ella no solo es creado lo inconsciente, sino, al mismo tiempo, el cuerpo infantil es dotado con excitabilidad sexual. Las respectivas estructuras deseantes que resultan de esto no conforman unidades estáticas, entidades homogéneas cerradas o definitivas, sino que, de acuerdo con el dictamen freudiano (Freud 1986, 229; Heller-Roazen 2005), son reescritas [umgeschrieben] una y otra vez a lo largo de la vida. Un punto nodal de estas reescrituras es conformado nada menos que por el conflicto de Edipo. Más concretamente, es posible interpretarlo como una respuesta -preliminar, inicial, inconclusa-a la situación de seducción a la que se aludió más arriba: efectivamente, tal como se ha ido desarrollando, el niño responde al ser-deseado por los padres con el forjamiento de su propio deseo ${ }^{7}$. Dicho de otra manera: el niño deseado, que, en estricto rigor, ni siquiera existe con anterioridad a esta experiencia pasiva de deseo, se convierte en el seductor, se apropia activamente lo que hasta entonces había padecido desde una posición de sujeción. Ante el telón de fondo de la impropiedad, de la extranjería y del no estar en casa, se convierte, entonces, en sujeto de su deseo, de modo que puede formular su deseo frente a los padres, enfrentando a los padres, confrontándolos.

En la estela abierta por la apropiación [Aneignung] psíquica descrita quisiéramos aprovechar de reformular la habitual recepción de las ideas freudianas que señala que en la fase fálica es solo un órgano genital el que posee relevancia -el pene. Si bien es cierto que es posible encontrar pasajes en los que Freud permanece en un nivel excesivamente concreto, al mismo tiempo no es posible obviar que, por lo general, tiene el necesario cuidado para desprender el concepto de falo del órgano genital masculino. La apropiación física del falo, en cambio, se refiere a ambos sexos y de manera universal remite al reconocimiento de tener un sexo. Es decir, no se trata de un sexo -como ha sido leído, y con justa razón, en Freud-, sino de un sexo, y, con ello, del reconocimiento de la capacidad de proporcionarse placer, por vías

7 El deseo, como sabemos a partir de Freud y como ha sido enfatizado por Lacan, nunca es propio, nunca es "de uno". 
polimorfas, que no estén necesariamente al servicio de la procreación, tanto a uno mismo como a otros.

\section{EL COMPLEJO DE EDIPO COMO MODELO ESTRUCTURAL UNIVERSAL}

En lo que sigue quisiéramos discutir la pregunta en qué medida el complejo de Edipo puede desprenderse de la heteronormatividad subyacente, con tal de ser (re)formulado como modelo estructural universal, y si es que la dicotomía de los sexos, la bipartición del sexo, adopta para este conflicto una significación constitutiva, imprescindible, a la que no puede renunciar.

Con la reformulación del conflicto de Edipo como respuesta a la seducción se torna posible disipar una objeción importante que frecuentemente es aducida en contra de la diversificación del sexo y la suspensión de la dicotomía de los sexos. Las cuasi infinitas posibilidades de asignarse o incluso inventarse una categoría sexual, tal como sucede, por ejemplo, en los medios sociales, parecen sugerir que las identificaciones de sexo son procesos arbitrarios que solamente dependen de la voluntad -y de los caprichos, las extravagancias y la arbitrariedad- del respectivo individuo. Desde un punto psicoanalítico, nada es más falso que esto ${ }^{8}$. Sin embargo, en su teoría del sexo, Laplanche (2011) subraya que el niño, al menos en un primer momento, presuntamente primordial, originario, no es que se identifique activamente, sino que es identificado por [identification by] los adultos y la sociedad que con su estructuración binaria precede al sujeto. La forma lingüística pasiva, la asignación mediante el, la o lo otro, más que ser un mero detalle, debido a la relevancia asignada al lenguaje en general y a la lengua en particular, es central en este punto. Con esto, el sexo -al igual que el deseo- no es algo que esté libremente disponible, que esté (dis)puesto al servicio de un sujeto autónomo, ya plenamente emancipado respecto de sus determinaciones históricas inconscientes, zur Hand, en cierto modo puesto ahí a gusto del consumidor, prêt-à-porter. Sin embargo, tampoco

\footnotetext{
En este sentido, hay una interesante diferencia en el uso del lenguaje en el caso del inglés, del castellano y del alemán: mientras que en alemán y en castellano uno se identifica 'con' [mit] algo o alguien, en inglés, en cambio, uno se identifica 'como' [as] algo o alguien. En estas formas del habla se muestra una relación, en cada caso distinta, entre el yo y el otro, ya que el yo en inglés, el $I$, aparece más activo, más autónomo, menos referido al otro.
} 
es que esté estructurado definitiva e insalvablemente desde el exterior mediante las operaciones descritas de asignación [Zuschreibung], sino que es creado -y desconstruido- en un interjuego complejo e incesante entre el yo y el, la o lo otro. Conviene distinguir, en ese sentido, el concepto de otro (con minúscula), que hace alusión tanto a la figura del otro, del Mit- o Nebenmensch, como a la persona concreta con su inconsciente, en cada caso individual, del Otro (con mayúscula), que remite básicamente a factores sobre todo sociales y culturales, tales como tradiciones, convenciones, instituciones y, sobre todo, el lenguaje $-y$, queremos agregar en este punto, las lenguas. Esta elaboración psíquica ocurre -como el trabajo psíquico en general-inconscientemente y, por consiguiente, no puede ser influenciado de manera intencional, al menos no en un sentido racional clásico. Más allá de esto, es de importancia vital que las múltiples asignaciones, con miras a la identidad sexual que una persona ha de procesar, elaborar y amortiguar, no ocurren en un mismo sentido ni en una misma dirección; así, por ejemplo, es de esperar que no se forje al modo de una entidad homogénea, armoniosa, estática, libre de contradicciones y tensiones, sino como un todo incompleto, abierto, que contiene al mismo tiempo elementos con connotaciones masculinas y femeninas, que pueden ser conscientes o inconscientes. Lo anterior en ningún caso desemboca en la causación de conflictos psíquicos manifiestos o incluso en trastornos o alteraciones pesquisables, sino que estas asignaciones sexuales múltiples están presentes en toda persona, tal como Freud ya explicitó en su concepto de una bisexualidad constituyente. Mientras que el concepto de bisexualidad 'a secas' sigue tributando a la idea de una dicotomía, establecida de una vez para siempre, de los sexos, la añadidura 'constitutiva' resulta ser de vital importancia, pues se refiere no solo a la dimensión psíquica o psicosocial, como ha sido documentado abundantemente, sino, no solo también sino primeramente, al nivel somático.

En efecto, la pluralidad, la disolución de toda idea de unidad ideal, ya comienza a nivel del sexo corporal. Porque, a diferencia de lo que ha sido desarrollado por Robert Stoller (1968) con su concepto de la core gender identity, el sexo del cuerpo, en este caso, en el sentido biológico, anatómico -es decir, el Körper, propiamente tal, y no el Leib- es algo compuesto [Zusammengesetztes] y, en ningún caso, un "núcleo", ni, mucho menos, un núcleo desintegrable, ininterrogable. Hasta la fecha, el concepto de identidad nuclear de sexo, salvo contadas excepciones, goza prácticamente de una validez indiscutible al interior del debate psicoanalítico en tanto un gold standard apenas interrogado, acaso intocable, que ejerce una resistencia no menor a la 
revisión crítica, radical, de ciertos preceptos del pensar ${ }^{9}$. Anudamos nuestras reflexiones, en este punto, a los esfuerzos de Reimut Reiche, que si bien fueron publicados en 1997 hasta la fecha han sido escasamente recepcionados, y quien mostró que dicho núcleo era, más bien, algo compuesto en distintos momentos y, por ende, altamente dinámico, señalando, entre otras críticas, que Stoller, lejos de describir un hecho científico, permaneció preso de sus prejuicios ideológicos y de sus preconceptos no reflexionados. En la línea de lo que hemos desarrollado, su crítica repara en la falta de consideración de la bisexualidad freudiana y en que el desarrollo de este núcleo, contrariamente a toda lógica psicoanalítica, que se piensa como teoría del conflicto, fuera pensado como algo "libre de conflictos". Desde la perspectiva de la teoría general de la seducción, así como de los múltiples mensajes referidos al sexo y las distintas asignaciones sociales, solo puede asentirse a lo anterior. Por ende, la idea de una conformación identitaria conforme -o no- a la Gestalt preconcebida del cuerpo impresiona simplemente como una creencia subcompleja, reduccionista, que despista y conduce a errores [irreführend].

A diferencia de la comprensión cotidiana, el sexo del cuerpo no representa una unidad monolítica, inseparable, sino que es, ya ella misma, algo construido, compuesto por distintos componentes. Porque el sexo corporal no solamente se refiere a los genitales, sino que comprehende otros factores y se compone, entre otros, de distintos factores anatómicos, morfológicos, endocrinológicos. Esta condición de estar-construido es una idea central para las reflexiones aquí expuestas. Por ende, no es sino un consenso o acuerdo social, en este caso, establecido en el orden de las ciencias naturales, entre ellas, la medicina, establecer qué dimensiones habrán de ser consideradas como constitutivas para el sexo -y cuáles no. Este acuerdo, ya sea logrado por la vía de la imposición o de la solución de compromiso, en ningún caso es estático ni estable, no es algo establecido por sobre todas los tiempos y culturas, sino que depende de un sinfín de aspectos coyunturales, accidentales, históricos,

\footnotetext{
¿De qué, exactamente, se trata este concepto? Pues, supone que en torno a un núcleo central, conformado por el sexo del cuerpo [sex], se depositan dos círculos o sedimentos concéntricos: el primero de ellos, que se deposita [legt sich] adyacentemente alrededor de este núcleo, ya sea acorde a la Gestalt del cuerpo, o sea, de manera isomorfa, o contradiciéndola, es decir, de manera anisomorfa, conforma un estrato que, a su vez, se convierte en núcleo: la identidad de género nuclear. Este (segundo) núcleo es envuelto, finalmente, por la llamada identidad de rol de género, la instancia responsable de integrar tanto las representaciones de sí mismo y de objeto, como a las convenciones sociales.
} 
como, por ejemplo, las posibilidades diagnósticas o tecnológicas. En este sentido, una vez más, el enunciado que en el caso del sexo se trata de algo construido, no se refiere solo al nivel psicológico o social, sino también al ámbito de lo corporal, algo para lo que abundan los ejemplos provenientes de la práctica clínica.

\section{CONCLUSIONES}

La conformación de la llamada identidad sexual, con todas las interrogantes irresueltas que esta expresión, presuntamente inequívoca, arrastra consigo, entonces, puede ser comprendida como un proceso integrativo, abierto y poroso, que si bien adquiere una mayor relevancia durante determinados momentos de la vida (por ejemplo, durante la temprana infancia, la edad preescolar y la adolescencia), sin embargo, es algo que se extiende a lo largo de toda la vida -y más allá de ella, al menos en lo relativo a sus orígenes.

La conceptualización, a ratos excesivamente esquemática y reduccionista, en ocasiones tendenciosa, del conflicto de Edipo gana en cuanto a su complejidad y plasticidad con la consideración de la situación de seducción que lo gatilla. El desglose de la estructura relacional que propone el Edipo, y a la que se accede atravesando las lecturas 'de contenido', da como resultado un conjunto móvil de posiciones, que se encentran puestas en un plexo relacional dinámico, dotado de múltiples posibilidades, que van más allá del determinismo causal lineal. Respecto de sus dos variantes, en lugar de complejo de Edipo positivo y negativo, dado el juicio de valor explícito que en ellos se expresa, preferimos hablar de una acuñación homosexual y otra heterosexual, a sabiendas de que esta formulación tampoco escapa a la matriz dicotómica que la determina. Si se quiere mantener la concepción convencional de la madre como figura de referencia primaria y el padre, en tanto función, como un tercero, entonces hay que tomar conciencia de que con esto al amor lésbico de la hija se le asignaría un rol más relevante que al amor heterosexual hacia el padre, es decir, que las mujeres "normalmente" tendrían que ser homosexuales, lo que no solamente es difícil de corroborar empíricamente, sino que teóricamente es un disparate. La salida [Ausgang] del complejo de Edipo, según Freud, reside en el establecimiento de la orientación sexual. Sin embargo, de acuerdo a la experiencia clínica y la investigación en ciencias sexuales, no es infrecuente que ocurran reiteradas modificaciones de la elección de objeto en el transcurso de la historia vital. Con tal de no estar obligado de reconducir 
a tales modificaciones al hecho que la persona respectiva haya suprimido su "tendencia verdadera [eigentlich]" o actuado en contra de su "verdadera inclinación", nos parece más razonable y sensato suponer que la orientación sexual no es establecida de manera inamovible de una vez por todas en el marco del complejo de Edipo en la temprana infancia respectivamente en la adolescencia, sino que -al igual que en toda estructura de deseo-representa el resultado de una serie reescrituras a lo largo de la historia. El conflicto de Edipo, más que ser resuelto definitivamente, en distintos momentos de la vida puede ser reactualizado o retomado, o también puede retornar, ante lo que se pueden generar soluciones en cada caso diferentes.

A partir de la relectura propuesta por Laplanche, el complejo de Edipo puede ser comprendido como giro copernicano en el terreno de la ontogénesis. Esto considera la introspección del descentramiento de la existencia humana y termina la fase ptolemaica de las estructuras diádicas relacionales, en la que el individuo se encuentra en el centro de sus relaciones, en cierto modo, conforma el punto de intersección en el cual se entrecruzan todas las relaciones. En el curso del conflicto de Edipo, su trazo, el sujeto, en un primer momento, no solo es descentrado, sino que es constituido descentradamente. Este paso posee una importancia decisiva para la ulterior conformación de la estructura psíquica, ya que forma la base para una 'vida en triángulo' como la forma fundamental de toda relación social. El niño, luego de ser emplazado en un primer momento, en un segundo instante se localiza activamente en la red social, ocupa un determinado lugar, al principio, al interior de las relaciones sociales, luego más allá de éstas en otros contextos relacionales sociales. Hasta entonces, el niño establece y habita exclusivamente relaciones diádicas, por muy diferentes que sean sus partenaires. La estructura relacional diádica frecuentemente es malinterpretada como una relación que se establecería, en primer lugar, solamente con una persona concreta, de carne y hueso, y, en segundo, solamente con una persona, la mayor parte de las veces, la madre, por lo que el padre es designado como el tercero. Más bien, se trata de que en un determinado momento de la constitución subjetiva, al encontrarse tomado por la diada, debido a su carácter envolvente y falto de afuera, la relación que los otros tienen entre sí, no posee relevancia alguna para el niño. Esta indiferencia o falta de referencialidad cambia radicalmente con el conflicto de Edipo. En esta "triangulación" y el consecuente descentramiento subjetivo yace su función conformadora de estructura, que ha de ser puesta lado a lado con la función constituyente de identidad, que está asociada al desarrollo de la orientación sexual y de la identidad de sexo. 
El carácter jánico del conflicto de Edipo se relaciona justamente con esta doble función de ser, por un lado, conformadora de estructura y, por el otro, constituyente de identidad. A nivel de la conformación de la estructura encontramos un acontecer tendiente al descentramiento, mientras que la constitución identitaria transcurre en dirección de un recentramiento. Dado que no hay sociedad que se las pueda arreglar sin principios ordenadores, el conflicto de Edipo aún posee una relevancia central en cuanto a la constitución de la cultura. Sin embargo, se impone la pregunta de si la constitución identitaria necesariamente tiene que ocurrir de manera heteronormativa o si los conceptos de identidad acaso no pueden ser concebidos tan abierta y fluidamente de modo que contengan lo no-idéntico, y que lo masculino y lo femenino, lo homosexual y lo heterosexual puedan coexistir conjuntamente. Movimientos de descentramiento orientados hacia el reconocimiento de lo otro y extraño, lo inaccesible, en esto alternan con sus respectivos procesos de recentramiento que apuntan al establecimiento de la constitución identitaria. Este permanente movimiento de abrir y cerrar, de descentramiento y recentramiento nos parece de importancia para una constitución identitaria dinámica, permanente, que no se delimita dicotómicamente del otro y que está en condiciones de admitir conjunta y simultáneamente la coexistencia de lo contradictorio.

\section{BIBLIOGRAFÍA}

Bornhauser, Niklas. “Acerca de la función emancipatoria y el estatuto crítico de la interpretación en psicoanálisis”. Alpha 29 (2009): 251-268.

Butler, Judith. The Psychic Life of Power: Theories in Subjection. Stanford, CA: Stanford University Press, 1977.

Canguilhem, Georges. Le normal et le pathologique. Paris: Presses Universitaires de France, 1996.

Freud, Sigmund. Drei Abhandlungen zur Sexualtheorie. En Gesammelte Werke V. Frankfurt am Main: Fischer, 1905.

Eine Kindheitserinnerung des Leonardo da Vinci. En Gesammelte Werke VIII. Frankfurt am Main: Fischer. 1910.

Vorlesungen zur Einführung in die Psychoanalyse. En Gesammelte Werke XI. Frankfurt am Main: Fischer, 1916-1917.

Das Ich und das Es. En Gesammelte Werke XIII. Frankfurt am Main: Fischer, 1923a.

Die infantile Genitalorganisation. En Gesammelte Werke XIII. Frankfurt am Main: Fischer, 1923b. 
Der Untergang des Ödipuskomplexes. En Gesammelte Werke XIII. Frankfurt am Main: Fischer, 1924.

Briefe an Wilhelm Fließ 1887-1904. Hrsg. v. Masson, J. M. Frankfurt am Main: Fischer, 1986.

Heller-Roazen, Daniel. Echolalias: On the Forgetting of Language. New York: Zone Books, 2005.

Horney, Karen. "Zur Genese des weiblichen Kastrationskomplexes". Internationale Zeitschrift für Psychoanalyse 9 (1923): 12-26.

Laplanche, Jean. Die unvollendete kopernikanische Wende in der Psychoanalyse. Frankfurt am Main: Suhrkamp, 1996.

Freud and the Sexual. New York, NY: International Psychoanalytic Books, 2011. Die allgemeine Verführungstheorie und andere Aufsätze. Tübingen: Diskord, 1988.

Laplanche, Jean y Jean-Bertrand Pontalis. Das Vokabular der Psychoanalyse. Frankfurt am Main: Suhrkamp, 1972.

Parin, Paul y Goldy Parin-Matthey. Subjekt im Widerspruch. Frankfurt/M.: Syndikat, 1986.

Quindeau, Ilka. Verführung und Begehren. Die psychoanalytische Sexualtheorie nach Freud. Stuttgart: Klett-Cotta, 2008.

Reiche, Reimut. “Gender ohne Sex. Geschichte, Funktion und Funktionswandel des Begriffs 'Gender'”. Psyche 51 (1997): 926-957.

Rohde-Dachser, Christa. "Psychoanalytische Theorien über die Differenz der Geschlechter". Psyche 43 (1989): 193-218.

Stoller, Robert. Sex and gender. On the development of masculinity and femininity. Bd.1. New York: Science House, 1968.

Vogt, Roland. Psychoanalyse zwischen Mythos und Aufklärung oder das Rätsel der Sphinx. Frankfurt/M.: Qumran, 1986. 